\title{
Mental health symptoms and inflammatory markers among HIV infected patients in Tanzania
}

Peter Memiah ${ }^{1,2^{*}}$ (D) Lillian Nkinda ${ }^{3}$, Mtebe Majigo $^{3}$, Felix Humwa ${ }^{4}$, Zelalem T. Haile ${ }^{5}$, Kennedy Muthoka ${ }^{6}$, Aisha Zuheri ${ }^{7}$, Anne Kamau ${ }^{8}$, Lucy Ochola ${ }^{9}$ and Gabriel Buluku ${ }^{9}$

\begin{abstract}
Background: HIV and mental disorders are predicted to be the leading causes of illness worldwide by the year 2030. HIV-infected patients are at increased risk of developing mental disorders which are significantly associated with negative clinical outcomes and propagation of new HIV infections. There is little evidence that links inflammation to development of mental disorders among HIV patients. Therefore, the main objective of this study was to evaluate if mental health symptoms were associated with biomarkers of inflammation in HIV infected subjects.

Methods: A cross-sectional study was conducted in Dar es Salam, Tanzania from March to May 2018. Standardized tools were used to collect data based on the World Health Organisation's (WHO) stepwise approach for noncommunicable diseases (NCD) surveillance. A total of $407 \mathrm{HIV}+$ patients on antiretroviral therapy were recruited. The WHO stepwise approach for NCD surveillance was used to collect data together with anthropometric measurements. Mental health symptoms were determined based on self-reported thoughts of helplessness, suicide ideation, depression, despair, discouragement, and feelings of isolation. Enzyme-linked immunosorbent assay was used to test for inflammatory markers:- C-reactive protein (CRP), linterleukin-6 (IL-6), interleukin-18 (IL-18), soluble tumour necrosis factor receptor-I (sTNFR-I), and soluble tumour necrosis factor receptor-II (sTNFR-II). Bivariate and multi-variate analysis was conducted to examine the association between biomarkers and mental health symptoms.
\end{abstract}

\footnotetext{
* Correspondence: pmemiah@ihv.umaryland.edu

The questionnaire for this study has been published in a publication [36]

from the same study.

${ }^{1}$ Division of Epidemiology and Prevention: Institute of Human Virology,

University of Maryland School of Medicine, 725 West Lombard Street, Room N459, Baltimore, MD 21201, USA

${ }^{2}$ Department of Medicine, University of Maryland Medical Centre Midtown Campus, Baltimore, MD, USA

Full list of author information is available at the end of the article
}

(c) The Author(s). 2021, Corrected publication 2021. Open Access This article is licensed under a Creative Commons Attribution 4.0 International License, which permits use, sharing, adaptation, distribution and reproduction in any medium or format, as long as you give appropriate credit to the original author(s) and the source, provide a link to the Creative Commons licence, and indicate if changes were made. The images or other third party material in this article are included in the article's Creative Commons licence, unless indicated otherwise in a credit line to the material. If material is not included in the article's Creative Commons licence and your intended use is not permitted by statutory regulation or exceeds the permitted use, you will need to obtain permission directly from the copyright holder. To view a copy of this licence, visit http://creativecommons.org/ licenses/by/4.0/. The Creative Commons Public Domain Dedication waiver (http://creativecommons.org/publicdomain/zero/1. 0/) applies to the data made available in this article, unless otherwise stated in a credit line to the data. 
Results: The prevalence of self-reported mental health symptoms was $42 \%(n=169)$. Participants with self-reported symptoms of mental health had elevated CRP, were less likely to walk or use a bicycle for at least 10 minutes, were less likely to participate in moderate-intensity sports or fitness activities, and had poor adherence to HIV treatment $(p<$ 0.005). CRP remained significant in the sex adjusted, age-sex adjusted, and age-sex-moderate exercise adjusted models. In the fully adjusted logistic regression model, self-reported mental health symptoms were significantly associated with a higher quartile of elevated CRP (OR 4.4; 95\% Cl 1.3-5.9) and sTNFR-II (OR 2.6; 95\% Cl 1.4-6.6) and the third quartile of IL-18 (OR 5.1;95\% Cl 1.5-17.5) as compared with those reporting no mental health symptoms. The significance of sTNFR-II and IL-18 in the fully adjusted model is confounded by viral load suppression rates at the sixth month.

Conclusion: High CRP and sTNFR II were important contributors to the prevalence of mental health symptoms. This study is among the minimal studies that have examined mental health issues in HIV, and therefore, the findings may offer significant knowledge despite the potential reverse causality. Regardless of the nature of these associations, efforts should be directed toward screening, referral, and follow-up of HIV patients who are at-risk for mental health disorders.

Keywords: Mental health, Inflammatory markers, People living with HIV, Antiretroviral, Dar Es Salaam

\section{Background}

Human immunodeficiency virus (HIV) and mental disorders are predicted to be the leading causes of illness worldwide by the year 2030 [1]. Tremendous progress has been made globally since HIV - type 1 (HIV-1) was discovered in 1983 [2], with acquired immunodeficiency syndrome (AIDS) related annual deaths declining by 33\% from 2010 to about 770,000 in 2018 [3, 4]. People living with HIV (PLHIV) face many negative experiences including stigma, discrimination, traumatic events, and mental health problems $[5,6]$. These negative experiences increase the risk of developing mental disorders in PLHIV [5, 6]. HIV un-infected people with mental health problems have a higher risk of HIV infection than the general population [7-10] with severe mental illness increasing the risk of HIV acquisition by 4 to 10 fold [11]. Psychiatric disorders among HIV-infected individuals are significantly associated with negative clinical outcomes including reduced highly active antiretroviral therapy (HAART) utilization, poor adherence to HAAR $\mathrm{T}$, and poor virological suppression $[6,12,13]$. On the other hand, mental health problems increase risky sexual behaviors like unprotected sex and multiple sexual partners which exacerbate the probability of spreading HIV $[5,6,14]$. Depressive symptoms are the most common form of mental disorders in HIV-1 infected patients and can also be a side effect of HAART $[6,13]$.

It is widely recognized that increased levels of inflammation are central to the development of mental health problems like depression [15-19]. Recent studies indicate a bi-directional relationship [20]. Notwithstanding, the evidence linking inflammation to mental disorders comes from observations of elevated levels of inflammatory markers in patients with mental health problems, co-occurrence of mental health problems with inflammatory illnesses, and increased risk of mental health problems with cytokine treatment [21, 22]. Following
HIV-1 infection, the establishment of immune activation and inflammation involve several mechanisms that are directly or indirectly related to viral replication [23]. High levels of pro-inflammatory cytokines, such as tumour necrosis factor alpha (TNF $\alpha$ ), interleukin 6 (IL6) and interleukin 1 beta (IL-1 $\beta$ ) in both plasma and lymph nodes, are observed from the early stages of HIV1 infection [24-26]. In vitro studies suggest that HIV gene products can induce directly the activation of lymphocytes and macrophages and the production of proinflammatory cytokines and chemokines [23, 24]. There is evidence to support the 'cytokine hypothesis of depression' which implies that pro-inflammatory cytokines, acting as neuromodulators, represent the key factor in the mediation of the behavioral, neuroendocrine, and neurochemical features of depressive disorders [27]. This hypothesis was emphasized by findings of increased plasma cytokines (IL-1 and IL-6) in the blood of depressed patients [28]. More robust research measuring direct markers of inflammation and mental health is needed among HIV-1 infected patients [15, 29].

Besides HIV/AIDS, there are other risk factors for increased risk of mental disorders. The impact of chronic stress and adverse life events on the onset of depression has been investigated repeatedly, partly influenced by studies of the somatic and endocrine consequences of stress in animals [16]. There is association of severely life-threatening events prior to onset of mental disorders such as depression, anxiety disorders, and affective disorders [30-32]. However, research has not shown the expected clear-cut difference in the presence of adverse life events provoking onset in depression [33]. The prevalence of depression is higher in females than males, and this cannot be explained by differing rates of exposure to stressful life events $[16,34]$. There is also evidence that genetic factors play an important role in the etiology of affective disorders [16, 35]. 
As there is strong evidence of deranged inflammatory response in HIV-1 as well as in mental health disorders, we set out to assess markers related to the inflammation in HIV-1 infected subjects with and without mental health symptoms. We posit that mental health symptoms lead to increased pro-inflammatory cytokine levels (CRP, IL-6, IL-18, sTNFR I, sTNFR II) in HIV-1 infected subjects.

\section{Methods}

\section{Study design, site, and population}

The study adopted a cross-sectional study design. Data was collected from PLHIV receiving treatment at the Infectious Disease Clinic (IDC) between March to May 2018. The Clinic is located in Dar es Salaam, Tanzania and provides care and treatment to a high proportion of PLHIV with an estimated 100 patients per day. Adults (> 18 years) living with HIV/AIDS, receiving care at IDC, and consented to be part of the study were included. The exclusion criteria was patients who were on antihypertensives and anti-inflammatory drugs within the past 3 months [36].

\section{Sample size and sampling technique}

This study recruited 407 HIV-positive study participants on Antiretroviral Therapy (ART). Purposive sampling was used whereby HIV patients attending appointments were screened, consented, and were recruited into the study.

\section{Data collection}

The study entailed quantitative data collection through survey, review of medical records, anthropometry, blood pressure assessments, and biochemical assessment of biomarkers in blood samples. The survey utilised the WHO Steps tool for NCD surveillance [37] to collect demographic and behavioural characteristics of participants [36]. Data on CD4 count, types, and duration of a ART was extracted from medical records. A trained nurse took blood pressure measurements as well as measurements of weight, height, and waist circumference.

\section{Blood pressure measurements}

Diastolic and systolic blood pressure measurements were taken using an Omron M2 (HEM-7121-E). This is a clinically validated automated blood pressure monitor. Two measurements were taken twice from the upper left arm at 3 minute intervals when the participant was seated and relaxed [36]. An average of the two readings was calculated and used in analysis. In order to diagnose hypertension, an average reading of greater than 140/90 mmHg was used.

\section{Anthropometric measurements}

Anthropometric measurements included waist and hip circumeference $(\mathrm{cm})$, body weight $(\mathrm{kg})$, and height (meters). Standard procedures of taking measurements were observed. For waist and height circumference measurements, waist to height ratio (WHR) was calculated in which $>50 \%$ was considered to represent an elevated WHR. Additionally, body mass index (BMI) was calculated based on weight and height, and the following cutoffs were used: under-weight $\left(\mathrm{BMI}<18 \mathrm{~kg} / \mathrm{m}^{2)}\right.$, normal $\left(\mathrm{BMI} \geq 18 \mathrm{~kg} / \mathrm{m}^{2}\right.$ and $\left.\leq 25 \mathrm{~kg} / \mathrm{m}^{2}\right)$, overweight $($ BMI $>25$ $\mathrm{kg} / \mathrm{m}^{2}$ and $<30 \mathrm{~kg} / \mathrm{m}^{2}$ ), and obese $\left(B M I \geq 30 \mathrm{~kg} / \mathrm{m}^{2}\right)$ [36].

\section{Blood sample collection and handling}

This part of the process entailed collection of venous blood by trained phlebotomists. The blood samples were collected into Ethylenediaminetetraacetic acid (EDTA) tubes. In order to obtain blood serum, the sample collected centrifuges for 20 minutes at $1000 \times \mathrm{g}$, and serum obtained was stored in cryo vials at $-80^{\circ} \mathrm{C}$. Using the Enzyme Linked Immunosorbent Assay (ELIS A) reader and the Multiskan Ascent reader 354-90,593 [36], anti-inflammatory markers, including interleukin 6 (IL-6), C-reactive protein (CRP), interleukin 18 (IL18), soluble tumour necrosis factor receptor type I (sTNFR-I) and type II (sTNFR-II), were tested. The laboratory procedures for analyzing these inflammatory markers are fully described in our related manuscript [36].

\section{Self-reported mental health symptoms}

The outcome variable was defined as feelings of depression, suicide ideation, low energy, helplessness, despair, and isolation in the last 30 days. We used the HIV Medical Outcomes Survey (MOS-HIV) which is a widely used and accepted measure for Health Related Quality of Life (HRQOL) in the HIV population [38]. The instrument has 35 items that assess the ten dimensions of health in individuals living with HIV (mental health, quality of life, health distress, cognitive function, and energy/fatigue). The outcome variable score was collapsed and categorized as a dichotomous variable with a "Yes" if the respondent answered yes to any of the questions on mental health and "No" if they answered no to all the questions. Some of the questions asked whether the participant was feeling down, depressed or hopeless; had poor appetite or overeating; had trouble concentrating on things such as reading; and had little interest or pleasure in doing things. The MOS-HIV tool was integrated with the WHO Stepwise approach tool [39], the primary tool for this study.

\section{Data analysis}

Microsoft Excel was used for entry of data from case reports forms and the ELISA reader. After which the data 
was clean and exported to STATA 14 (StataCorp, College Station, Texas) for coding and statistical analysis. Descriptive analysis of patient characteristics was performed using frequencies, percentages, median, and interquartile range. Analysis of inflammatory markers entailed stratification of the data into centiles then frequencies and percentages derived. Chi-square tests were used to determine whether there were any differences by sex and mental health status. At the multivariate level, four models, including sex-adjusted, age-sex adjusted, age-sex-moderate exercise adjusted, and the full multivariable model that included only covariates that had a priori $p$-value $<0.1$ with mental health in the univariate models, were utilised. Unadjusted and adjusted odds ratios (OR) were utilised to report associations between the variables. A $p$-value $<0.05$ was statistically significant.

\section{Result}

\section{Participants characteristics - males vs females}

We collected data from 407 participants, 99 males and 308 females, and summarized their characteristics in Table 1. Compared to females, males were less likely to be both overweight $(21.4 \%$ vs $27.7 \% ; P<0.001)$ and obese $(5.1 \%$ vs $18.6 \% ; P<0.001)$, respectively. There was a higher proportion of males compared to females in participants who were over 55 years $(67.7 \%$ vs $59.7 \%$; $P<0.037$ ). Male participants had less prevalent abnormal waist hip ratio compared to female participants (16.3\% vs $97.1 \%$; $P<0.001)$. Compared to females, male participants had a greater prevalence of currently smoking tobacco products $(9.1 \%$ vs $1 \% ; P<0.001)$, consumption of alcohol within past 12 months $(35.5 \%$ vs $15.7 \%$; $P<0.01$ ), and consumption of alcohol within the past 30 days $(19.4 \%$ vs $9.8 \% ; P<0.05)$.

Compared to males, females were less likely to be involved in vigorous-intensity work $(13.1 \%$ vs $1.6 \%$; $P<$ 0.001 ). Male participants were more likely to walk or use a bicycle for at least 10 minutes compared to female participants $(57.6 \%$ vs $41.2 \%$; $P<0.05)$. Compared to males, females were less likely to participate in moderateintensity sports or fitness activities $(13.1 \%$ vs $2.9 \%: P<$ 0.001 ). Males were more likely to have elevated TNR-2 as compared to females $(23.3 \%$ vs $21.3 \% ; P<0.05)$ as indicated in Table 2.

\section{Participants' characteristics - self reported mental health symptoms vs no mental health symptoms}

169 (42\%) participants had self-reported mental health symptoms compared to 233 (58\%) participants who reported none. Participants with self-reported symptoms of mental health had elevated CRP $(32.1 \%$ vs $19.1 \%$; $P<$ 0.05) compared to those without. Participants with selfreported mental health symptoms were less likely to walk or use a bicycle for at least 10 minutes compared to those without $(36.7 \%$ vs $51.9 \% ; P<0.05)$. Compared to those with self-reported mental health symptoms, participants without mental illness were less likely to participate in moderate-intensity sports or fitness activities (7.1\% vs $2.1 \%: P<0.05)$ and vigorous activities $(8.3 \%$ vs 3\%: $P<0.05)$.

Participants with self-reported mental health symptoms had lower ART adherence in the past week (14.9\% vs $4.3 \% ; P<0.05)$ and in the past month $(18.9 \%$ vs 11.2\%; $P<0.05)$ compared with those without mental health symptoms (Table 3 ).

There was a significant difference in elevated CRP $(p=0.013)$ and sTNFR-II $(p=0.036)$ between participants who had mental health symptoms and no health symptoms (Table 4).

\section{Odds ratio tables}

In the sex-adjusted model, CRP was significant (OR 2.27; 95\% CI 1.24-4.16) and was also observed to be significant in the age-sex adjusted model (OR 2.14; 95\% CI 1.15-3.96) and the age-sex-moderate exercise model (OR 2.14; 95\% CI 1.14-4). No other significant associations between biomarkers (pro-inflammatory markers) and self-reported mental health symptoms were present after multivariable adjustment. In the full adjusted logistic regression model, those in the highest quartile $(\mathrm{Q} 4)$ of CRP (OR 4.37; 95\% CI 1.28-5.88) and TNR-2 (OR 2.61; 95\% CI 1.39-6.66) had a higher odds of having mental health symptoms (Table 5).

\section{Discussion}

CRP has long been regarded as an acute phase protein indicative of ongoing infectious or inflammatory disease states, and is an identified marker associated with HIV disease [36, 40-44]. In a purposive sample of HIV positive Tanzanian adults, we found that elevated levels of CRP were positively associated with self-reported mental health symptoms. The observed association was independent of potential confounders such as age, WHR, physical activity, family history of diabetes, viral load (VL), and TNR2. To our knowledge, this study is the first to report on the positive association between CRP and self-reported mental health symptoms among HIV patients in Tanzania. This is consistent with data from the Korean National Health and Nutrition Examination Survey (KNH\&NES) which correlated elevation in hs-CRP with mobility problems and suicidal ideation leading to decreased quality of life and mental health problems [45]. Despite other inflammatory markers (IL6, IL-18, and sTNFR-I) assessed in our study not showing any significant association with mental health symptoms, other studies have shown a link between these markers and mental health symptoms [46-52]. 
Table 1 Characteristics of mental health symptoms among HIV+ patients in Tanzania

\begin{tabular}{|c|c|c|c|c|c|c|}
\hline Characteristic & Male \% $(n)$ & Female $\%(n)$ & $p$ value & Has Mental Health Symptoms & No Mental Health Symptoms & $p$ value \\
\hline Total & $24.3(99)$ & 75.7 (308) & & $42.0(169)$ & $58.0(233)$ & 0.037 \\
\hline \multicolumn{6}{|l|}{ Age Categories } & 0.085 \\
\hline $18-24$ Yrs & $4.0(4)$ & $1.0(3)$ & & $1.2(2)$ & $2.1(5)$ & \\
\hline $25-34$ Yrs & $7.1(7)$ & $6.2(19)$ & & $3.0(5)$ & $9.0(21)$ & \\
\hline $35-44$ Yrs & $21.2(21)$ & $33.1(102)$ & & $31.4(53)$ & $29.6(69)$ & \\
\hline $55+$ Yrs & $67.7(67)$ & $59.7(184)$ & & $64.5(109)$ & $59.2(138)$ & \\
\hline \multicolumn{3}{|l|}{ Age } & 0.180 & & & 0.870 \\
\hline Median (IQR) & 48.0. $(43-54)$ & $46.0(42-52)$ & & $47.0(42-53)$ & $46.0(41-52)$ & \\
\hline \multicolumn{3}{|l|}{ BMI Categories $(n=405)$} & $<0.001$ & & & 0.629 \\
\hline Underweight & $4.1(4)$ & $8.5(26)$ & & $8.3(14)$ & $6.5(15)$ & \\
\hline Normal & $69.4(68)$ & $45.3(139)$ & & $53.0(89)$ & $50.0(116)$ & \\
\hline Overweight & $21.4(21)$ & $27.7(85)$ & & $25.6(43)$ & $26.3(61)$ & \\
\hline Obesity & $5.1(5)$ & $18.6(57)$ & & $13.1(22)$ & $17.2(40)$ & \\
\hline \multicolumn{3}{|l|}{ Waist to Hip ratio indicator } & $<0.001$ & & & 0.099 \\
\hline Abnormal & $16.3(16)$ & $97.1(298)$ & & $81.5(137)$ & $74.6(173)$ & \\
\hline Normal & $83.7(82)$ & $2.9(9)$ & & $18.5(31)$ & $25.4(59)$ & \\
\hline \multicolumn{3}{|l|}{ Years spent at school } & $<0.001$ & & & 0.200 \\
\hline Median (IQR) & $7.0(7-11)$ & $7.0(7-7)$ & & $7.0(7-7)$ & $7.0(7-9)$ & \\
\hline \multicolumn{3}{|c|}{ Ever consumed any alcohol $(n=405)$} & 0.286 & & & 0.264 \\
\hline Yes & $62.6(62)$ & $56.5(173)$ & & $54.8(92)$ & $60.3(140)$ & \\
\hline No & $37.4(37)$ & $43.5(133)$ & & $45.2(76)$ & $39.7(92)$ & \\
\hline \multicolumn{3}{|c|}{ Consumed alcohol within 12 months? $(n=234)$} & 0.001 & & & 0.340 \\
\hline Yes & $35.5(22)$ & $15.7(27)$ & & $23.9(22)$ & $18.7(26)$ & \\
\hline No & $64.5(40)$ & $84.3(145)$ & & $76.1(70)$ & $81.3(113)$ & \\
\hline \multicolumn{3}{|c|}{ Alcohol frequency within 12 months $(n=49)$} & 0.820 & & & 0.525 \\
\hline Daily & $4.5(1)$ & $0(0)$ & & $0.0(0)$ & $3.8(1)$ & \\
\hline 5-6 days per week & $4.5(1)$ & $3.7(1)$ & & $9.1(2)$ & 0.0. (0) & \\
\hline 3-4 days per week & $4.5(1)$ & $7.4(2)$ & & $4.5(1)$ & $7.7(2)$ & \\
\hline 1-2 days per week & $27.3(6)$ & $29.6(8)$ & & $22.7(5)$ & $34.6(9)$ & \\
\hline $1-3$ days per month & $27.3(6)$ & $37(10)$ & & $36.4(8)$ & $30.8(8)$ & \\
\hline Less than once a month & $31.8(7)$ & $22.2(6)$ & & $27.3(6)$ & $23.1(6)$ & \\
\hline \multicolumn{3}{|c|}{ Consumed alcohol within $\mathbf{3 0}$ days? $(n=235)$} & 0.050 & & & 0.543 \\
\hline Yes & $19.4(12)$ & $9.8(17)$ & & $14.1(13)$ & $11.4(16)$ & \\
\hline No & $80.6(50)$ & $90.2(156)$ & & $85.9(79)$ & $88.6(124)$ & \\
\hline
\end{tabular}

Notwithstanding, none of the studies were conducted among HIV populations.

Despite the complicated and unexplored link between mental health and inflammation, activation of the sTNFR-II in patients with chronic inflammatory conditions appears to mediate depression through stimulation of a neuronal serotonin pathway leading to depletion of tryptophan $[20,53]$. This may help explain the significant association between sTNFR-II levels and mental health symptoms in our study population. If uninterrupted, sustained elevations of sTNFR-II have been postulated to lead to smaller hippocampal volumes and ultimately cognitive impairment [54].

While the pathogenesis of mental illness is not clearly understood, the association of CRP, sTNFR-II, and mental health symptoms in the study population suggests an association between a proinflammatory state and psychological distress in the population [55]. This may stem 
Table 2 Characteristics of mental health symptoms and physical activity among HIV+ patients in Tanzania

\begin{tabular}{|c|c|c|c|c|c|c|}
\hline Characteristic & Male \% (n) & Female $\%(n)$ & $p$ value & $\begin{array}{l}\text { Has Mental } \\
\text { Health Symptoms }\end{array}$ & $\begin{array}{l}\text { No Mental Health } \\
\text { Symptoms }\end{array}$ & $p$ value \\
\hline \multicolumn{3}{|c|}{ Does your work involve vigorous-intensity activity? } & $<0.001$ & & & 0.565 \\
\hline Yes & $13.1(13)$ & $1.6(5)$ & & $3.6(6)$ & $4.7(11)$ & \\
\hline No & $86.9(86)$ & $98.4(303)$ & & $96.4(163)$ & $95.3(222)$ & \\
\hline \multicolumn{3}{|c|}{ Does your work involve moderate-intensity activity? } & 0.280 & & & 0.564 \\
\hline Yes & $39.4(39)$ & $33.4(103)$ & & $36.7(62)$ & $33.9(79)$ & \\
\hline No & $60.6(60)$ & $66.6(205)$ & & $63.3(107)$ & $66.1(154)$ & \\
\hline \multicolumn{3}{|c|}{ In a typical week, on how many days do you do moderate-intensity activities? } & 0.090 & & & 0.060 \\
\hline median (IQR) & $1.5(0-6)$ & $0.0(0-6)$ & & $0.0(0-6)$ & $0.0(0-5)$ & \\
\hline \multicolumn{3}{|c|}{ Do you walk or use a bicycle (pedal cycle) for at least 10 minutes continuously? } & 0.004 & & & 0.002 \\
\hline Yes & $57.6(57)$ & $41.2(127)$ & & $36.7(62)$ & $51.9(121)$ & \\
\hline No & $42.4(42)$ & $58.8(181)$ & & $63.3(107)$ & $48.1(112)$ & \\
\hline \multicolumn{3}{|c|}{$\begin{array}{l}\text { Do you do any vigorous-intensity sports, fitness, or recreational (leisure) } \\
\text { activities? }\end{array}$} & $<0.001$ & & & 0.019 \\
\hline Yes & $13.1(13)$ & $2.9(9)$ & & $8.3(14)$ & $3(7)$ & \\
\hline No & $86.9(86)$ & 97.1 (299) & & 91.7 (155) & 97 (226) & \\
\hline \multicolumn{3}{|c|}{$\begin{array}{l}\text { Do you do any moderate-intensity sports, fitness, or recreational (leisure) activ- } \\
\text { ities? }(n=406)\end{array}$} & 0.712 & & & 0.014 \\
\hline Yes & $5.1(5)$ & $4.2(13)$ & & $7.1(12)$ & $2.1(5)$ & \\
\hline No & $94.9(93)$ & $95.8(295)$ & & 92.9 (156) & 97.9 (228) & \\
\hline
\end{tabular}

from an increase in the production of kynurenic and quinolinic acids associated with activation of the enzyme indoleamine-2,3-dioxygenase that leads to a reduction in the production of serotonin, which contributes to the development of depression [56, 57]. Further, increased neurotransmitter glutamate is associated with an increase in the production of kynurenic and quinolinic acids and may result in reduced brain-derived neurotrophic factor that is widely associated with depression [58].

It is also possible that the observed association could be due to reverse causality. Having symptoms of mental health may lead to increased inflammation [59-62]. Stress hormones released during psychological stress may trigger systemic inflammation resulting in elevated levels of CRP and sTNFR-II [63]. On the other hand, HIV disease itself may serve as a trigger for inflammation that may affect mental health. Even in the era of widespread use of ART, neuropsychiatric conditions, such as anxiety disorders, manic symptoms, atypical psychosis, or depression, continue to occur in HIV patients [64, 65]. Compared to the general population, significantly higher rates of mental health disorders have been reported among PLWH elsewhere. Among PLWH in Uganda, the prevalence of major depression was $14 \%$ [66]. Approximately, $26-38 \%$ of PLWH in South Africa have a mental disorder [67]. In India and China, the prevalence of depression symptoms among PLWH were $59 \%$ and $61 \%$ of PLWH, respectively $[68,69]$.

Regardless of the nature of the relationship between inflammation and mental health, our study findings support the need to screen HIV infected patients for symptoms and provide follow-up care as part of of HIV care. There is a plethora of well-established and validated instruments for mental health screening that can be utilized in low-and middle-income countries (LMICs) [70]. The results also support the need for additional intervention studies aimed at improving mental health outcomes in HIV patients.

Our study was limited by lack of a validated instrument or diagnostic scoring scale to measure specific mental health outcomes such as anxiety, psychological distress, or depression. Given the cross-sectional nature of the study, we cannot establish the direction of the relationship between CRP and sTNFR-II and mental health outcomes. The main outcome of interest, symptoms of mental health, was based on self-report, which is susceptible to social desirability and self-report bias. Additionally, purposive sampling may have introduced selection bias. As such, results may not be generalizable to the entire PLWH population in Tanzania. Finally, the observed association might also be due to unmeasured confounding, such as antidepressant use, and other factors associated with mental health outcomes that was not collected for this study. Despite these limitations our 


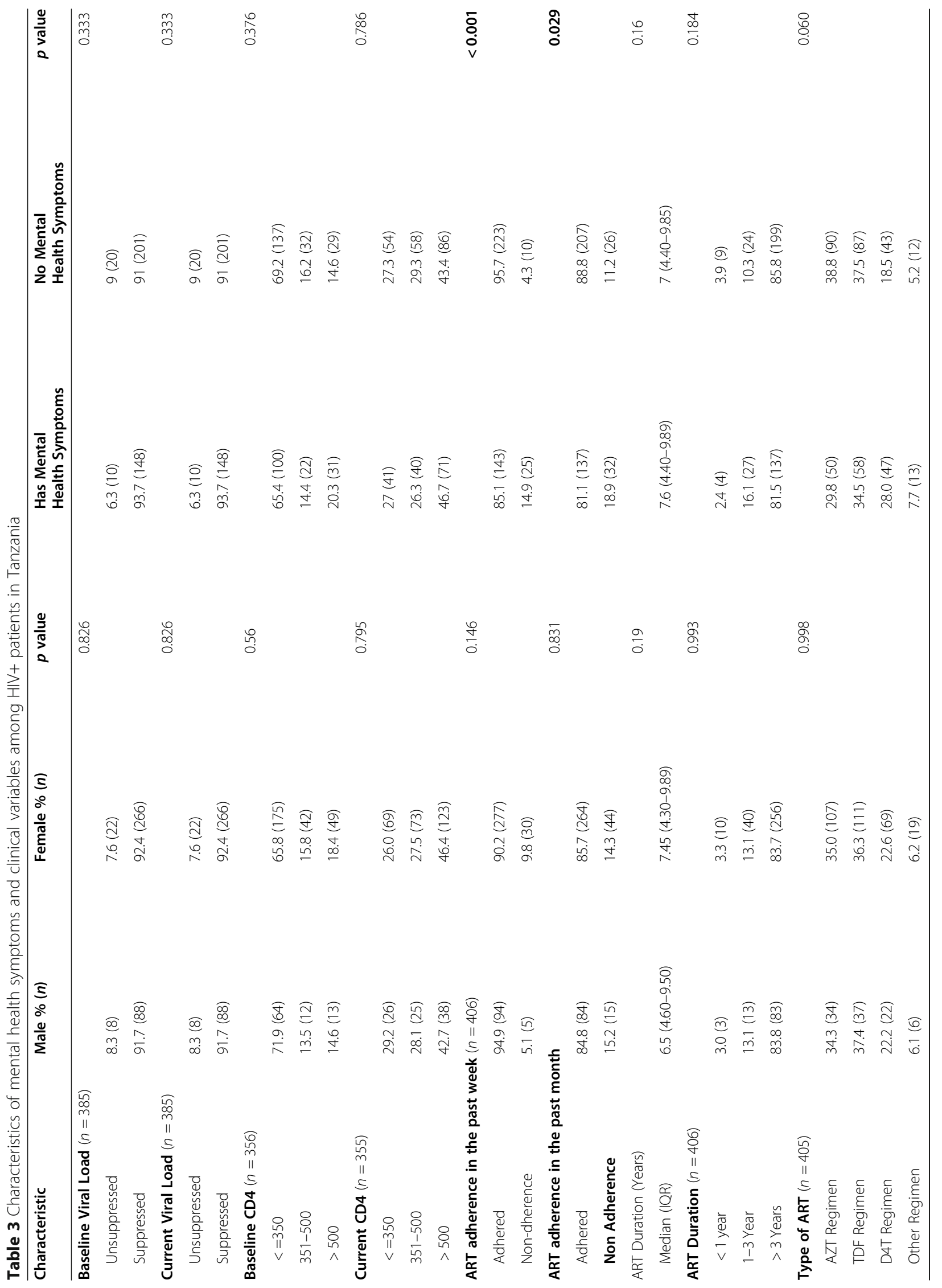


Table 4 Characteristics of mental health symptoms and inflammatory markers among HIV+ patients in Tanzania

\begin{tabular}{|c|c|c|c|c|c|c|}
\hline Characteristic & Male \% (n) & Female \% (n) & $p$ value & Has Mental Health Symptoms & No Mental Health Symptoms & $p$ value \\
\hline $\operatorname{CRP}(n=404)$ & & & 0.919 & & & 0.013 \\
\hline Q1 & $27.8(25)$ & $26.0(78)$ & & $23(38)$ & $29.1(64)$ & \\
\hline Average & $46.7(42)$ & $49.0(147)$ & & $44.8(74)$ & $51.8(114)$ & \\
\hline Q4 & $25.6(23)$ & $25.0(75)$ & & $32.1(53)$ & $19.1(42)$ & \\
\hline IL $6(n=404)$ & & & 0.452 & & & 0.809 \\
\hline Q1 & $24.4(22)$ & $28.3(85)$ & & $27.9(46)$ & $26.4(58)$ & \\
\hline Average & $52.2(47)$ & $44.7(134)$ & & $44.8(74)$ & $48.2(106)$ & \\
\hline Q4 & $23.3(21)$ & $27.0(81)$ & & $27.3(45)$ & $25.5(56)$ & \\
\hline IL $18(n=403)$ & & & 0.509 & & & 0.718 \\
\hline Q1 & $21.1(19)$ & $26.4(79)$ & & $23.6(39)$ & $26.5(58)$ & \\
\hline Average & $54.4(49)$ & $48.2(144)$ & & $51.5(85)$ & $47.5(104)$ & \\
\hline Q4 & $24.4(22)$ & $25.4(76)$ & & $24.8(41)$ & $26(57)$ & \\
\hline TNR $1(n=404)$ & & & 0.181 & & & 0.509 \\
\hline Q1 & $26.7(24)$ & $25.3(76)$ & & $23(38)$ & $27.7(61)$ & \\
\hline Average & $41.1(37)$ & $51(153)$ & & $49.1(81)$ & $48.2(106)$ & \\
\hline Q4 & $32.2(29)$ & $23.7(71)$ & & $27.9(46)$ & $24.1(53)$ & \\
\hline TNR $2(n=404)$ & & & 0.01 & & & 0.036 \\
\hline Q1 & $13.3(12)$ & $29(87)$ & & $27.3(45)$ & $24.1(53)$ & \\
\hline Average & $63.3(57)$ & 49.7 (149) & & $55.8(92)$ & $50.5(111)$ & \\
\hline Q4 & $23.3(21)$ & $21.3(64)$ & & $17(28)$ & $25.5(56)$ & \\
\hline
\end{tabular}

Table 5 Logistic regression on mental health symptoms

\begin{tabular}{|c|c|c|c|c|c|c|c|c|}
\hline Biomarker & Sex-Adjusted & $p$ value & Age-Sex Adjusted & $p$ value & $\begin{array}{l}\text { Age-Sex-Moderate } \\
\text { Exercise Adjusted Model }\end{array}$ & $p$ value & Full Model* & $p$ value \\
\hline \multicolumn{9}{|l|}{ CRP } \\
\hline Q3 & $1.10(0.66-1.82)$ & 0.717 & $1.08(0.64-1.81)$ & 0.783 & $1.12(0.66-1.89)$ & 0.673 & $1.11(0.38-3.27)$ & 0.85 \\
\hline Q4 & $2.27(1.24-4.16)$ & 0.008 & $2.14(1.15-3.96)$ & 0.016 & $2.14(1.14-4)$ & 0.018 & $4.37(1.28-5.88)$ & 0.018 \\
\hline \multicolumn{9}{|l|}{ TNR 1} \\
\hline Q3 & $1.09(0.65-1.83)$ & 0.734 & $1.10(0.65-1.86)$ & 0.715 & $1.04(0.61-1.76)$ & 0.897 & $1.71(0.53-5.5)$ & 0.366 \\
\hline Q4 & $1.54(0.85-2.77)$ & 0.152 & $1.51(0.84-2.73)$ & 0.172 & $1.45(0.8-2.64)$ & 0.221 & $1.87(0.55-6.36)$ & 0.316 \\
\hline \multicolumn{9}{|l|}{ TNR 2} \\
\hline Q3 & $1.01(0.61-1.7)$ & 0.958 & $1.06(0.63-1.78)$ & 0.835 & $1.08(0.64-1.82)$ & 0.783 & $1.48(0.49-4.53)$ & 0.487 \\
\hline Q4 & $1.66(0.35-1.85)$ & 0.202 & $1.71(0.37-1.85)$ & 0.295 & $1.79(0.36-1.93)$ & 0.266 & $2.61(1.39-6.66)$ & 0.013 \\
\hline \multicolumn{9}{|l|}{ IL 6} \\
\hline Q3 & $0.84(0.51-1.38)$ & 0.487 & $0.86(0.52-1.43)$ & 0.566 & $0.90(0.54-1.51)$ & 0.694 & $1.33(0.45-3.9)$ & 0.609 \\
\hline Q4 & $0.81(0.45-1.45)$ & 0.473 & $0.83(0.46-1.5)$ & 0.544 & $0.84(0.46-1.53)$ & 0.577 & $0.71(0.22-2.35)$ & 0.577 \\
\hline \multicolumn{9}{|l|}{ IL 18} \\
\hline Q3 & $1.32(0.79-2.2)$ & 0.293 & $1.26(0.75-2.12)$ & 0.378 & $1.24(0.73-2.09)$ & 0.424 & $5.14(1.51-17.52)$ & 0.009 \\
\hline Q4 & $1.36(0.74-2.49)$ & 0.316 & $1.26(0.68-2.33)$ & 0.46 & $1.22(0.66-2.28)$ & 0.522 & $3.30(0.7-15.49)$ & 0.13 \\
\hline
\end{tabular}

*Dull model was adjusted for sex, age, moderate exercise, parent with type II diabetes, WHR, viral load copies at 6 months, vigorous-intensity sports, and weekly walking and cycling

*The reference group for all models was Q1 
study is strengthened by being amongst the pioneer studies that show an association between inflammation and mental health symptoms among PLWH from a HIV high-burden country.

\section{Conclusion}

Our study found that in a sample of Tanzanian adults, elevated levels of pro-inflammatory cytokines, including CRP and sTNFR-II, was positively associated with selfreported mental health symptoms, independent of confounding. However, due to potential reverse causality and confounding, findings from the current study should be interpreted with caution. Regardless of the nature of these associations, efforts should be made to screen for mental health disorders in HIV patients with structured follow-up for those found at risk.

\section{Abbreviations \\ AIDS: Acquired Immunodeficiency Syndrome; ART: Antiretroviral Therapy; BMI: Body Mass Index; Cl: Confidence Interval; CRP: C-reactive Protein; CRF: Case Report Forms; EDTA: Ethylenediaminetetraacetic Acid; ELISA: Enzyme-Linked Immunosorbent Assay; HAART: Highly Active Antiretroviral Therapy; HIV: Human Immunodeficiency Virus; HIV-1: Human Immunodeficiency Virus Type 1; HRQOL: Health-Related Quality of Life; IDC: Infectious Disease Clinic; IL-6: Interleukin-6; IL-18: Interleukin-18; MBL: Medical and Biological Laboratories; MOS-HIV: Medical Outcomes Survey for HIV; NCD: Non-Communicable Disease; OR: Odds Ratio; PLHIV: People Living with HIV; STNFR I: Soluble Tumour Necrosis Factor Receptor-I; sTNFRII: Soluble Tumour Necrosis Factor Receptor-II; WHO: World Health Organization; WHR: Waist to Height Ratio}

\section{Acknowledgements}

We are grateful to all clients who participated in the study. Our sincere gratitude also goes to health workers at IDC for cooperation and assistance in recruitment and specimen collection. We thank the Centre for Research and Economic Opportunity for funding this study. We also thank the AIMS Institute and CODESRIA for providing time support to the lead author in order to perform the study. Further, we acknowledge Dr. Carol Kingori from Ohio University who participated in the protocol development and the study design, conducting a similar study in Ghana. We thank Bio-Techne for ensuring the efficient shipment of the Biomarker kits to Muhimbili Laboratory for specimen testing. Finally, the lead author acknowledges support from the National Institutes of Health R25 fellowship programs- HIV Intervention Science Training Program for Underrepresented New Investigators (HISTP program) and the Program to Increase Diversity in Behavioral Medicine and Sleep Disorders Research (PRIDE program).

\section{Authors' contributions}

PM conceived the study, interpreted the data, drafted the manuscript, and critically reviewed of the manuscript. PM and FH performed the analysis. AZ, $L N$, and $M M$ contributed in managing the study, data collection, and critical review of the manuscript. PM helped in preparing the first draft of the manuscript. GB, AK, KM, ZH, and LN helped in critically reviewing the manuscript and meeting journal specifications. All authors participated in the critical appraisal and revision of the manuscript. All authors have read and approved the manuscript.

\section{Funding}

The study was partially supported through funding from the Centre for Research and Economic Opportunity. The funder supported in purchase of the tests for biomarker testing.

\section{Availability of data and materials}

Data used in the analyses for this study are available upon request from the corresponding author.

\section{Declarations}

\section{Ethics approval and consent to participate}

Approval for this study was obtained from the Muhimbili University Institutional Review Board12-06/AECNol.XII/86 and the University of West Florida Institutional Review Board. Prior to enrollment in the study, participants provided a written informed consent. All ethical procedures were conducted and maintained throughout the study period.

\section{Consent for publication}

Not applicable

\section{Competing interests}

The authors declare that they have no competing interests.

\section{Author details}

'Division of Epidemiology and Prevention: Institute of Human Virology, University of Maryland School of Medicine, 725 West Lombard Street, Room N459, Baltimore, MD 21201, USA. ${ }^{2}$ Department of Medicine, University of Maryland Medical Centre Midtown Campus, Baltimore, MD, USA.

${ }^{3}$ Department of Microbiology and Immunology, Muhimbili University of Health and Allied Sciences, Dar es Salaam, Tanzania. ${ }^{4}$ Global Program for Research Teaching, University of California San Francisco, Nairobi, Kenya. ${ }^{5}$ Department of Social Medicine, Ohio University Heritage College of Osteopathic Medicine, Dublin, OH, USA. 'Palladium Group, Nairobi, Kenya. ${ }^{7}$ Infectious Disease Centre, Dar es Salaam, Tanzania. ${ }^{8}$ University of Nairobi, Institute for Development Studies, Nairobi, Kenya. ${ }^{9}$ Institute of Primate Research, Nairobi, Kenya.

Received: 2 April 2020 Accepted: 14 May 2021

Published online: 10 June 2021

\section{References}

1. Mathers $C D$, Loncar D. Projections of global mortality and burden of disease from 2002 to 2030. PLoS Med. 2006;3(11):e442. https://doi.org/10.1371/ journal.pmed.0030442.

2. Barré-Sinoussi F, Chermann JC, Rey F, Nugeyre MT, Chamaret S, Gruest J, et al. Isolation of a T-Lymphotropic Retrovirus from a Patient at Risk for Acquired Immune Deficiency Syndrome (AIDS) Isolation of a TLymphotropic Retrovirus from a Patient at Risk for Acquired Immune Deficiency Syndrome (AIDS). Science. 1983;220(4599):868-71.

3. World Health Organization. Progress report on HIV, viral hepatitis and sexually transmitted infections, vol. 2019; 2019. p. 2016-21.

4. United Nations Joint Programme on HIV/AIDS (UNAIDS). UNAIDS Data. 2019;2019:476.

5. Whetten K, Reif S, Whetten R, Murphy-Mcmillan LK. Trauma, mental health, distrust, and stigma among HIV-positive persons: implications for effective care. Psychosom Med. 2008;70(5):531-8. https://doi.org/10.1097/PSY.0b013 e31817749dc.

6. Schadé A, van Grootheest G, Smit JH. HIV-infected mental health patients: characteristics and comparison with HIV-infected patients from the general population and non-infected mental health patients. BMC Psychiatry. 2013; 13(1):35. https://doi.org/10.1186/1471-244X-13-35.

7. Elkington KS, McKinnon K, Mann CG, Collins PY, Leu C-S, Wainberg ML. Perceived mental illness stigma and HIV risk behaviors among adult psychiatric outpatients in Rio de Janeiro, Brazil. Community Ment Health J. 2010;46(1):56-64. https://doi.org/10.1007/s10597-009-9209-4.

8. Wainberg ML, Cournos F, Wall MM, Pala AN, Mann CG, Pinto D, et al. Mental illness sexual stigma: implications for health and recovery. Psychiatr Rehabil J. 2016;39(2):90-6. https://doi.org/10.1037/prj0000168.

9. Bonfils KA, Firmin RL, Salyers MP, Eric R. Sexuality and intimacy among people living with serious mental illnesses: Factors contributing to sexual activity. Psychiatr Rehabil J. 2015; 38(3): 249-255.

10. Ciesla JA, Roberts JE. Meta-Analysis of the Relationship Between HIV Infection and Risk for Depressive Disorders. 2001;158(5):725-30.

11. Remien RH, Stirratt MJ, Nguyen N, Robbins RN, Pala AN, Mellins CA. Mental health and HIV/AIDS: the need for an integrated response. AIDS. 2019;33(9): 1411-20. https://doi.org/10.1097/QAD.0000000000002227.

12. Chander G, Himelhoch S, Moore RD. Substance abuse and psychiatric disorders in HIV-positive patients. Drugs. 2006;66(6):769-89. https://doi.org/1 0.2165/00003495-200666060-00004. 
13. Jayarajan N, Chandra PS. HIV and mental health: An overview of research from India. Indian J Psychiatry. 2010;52(Suppl1):S269-S273.

14. Lee Y-H, Salman A, Fitzpatrick JJ. HIV/AIDS preventive self-efficacy, depressive symptoms, and risky sexual behavior in adolescents: a crosssectional questionnaire survey. Int J Nurs Stud. 2009;46(5):653-60. https:// doi.org/10.1016/j.jinurstu.2008.11.007.

15. Preez A Du, Leveson J, Zunszain PA, Pariante CM. Inflammatory insults and mental health consequences: does timing matter when it comes to depression?. Psychol Med. 2016;46(10):2041-57.

16. Bondy B. Pathophysiology of depression and mechanisms of treatment. Dialogues Clin Neurosci. 2002;4(1):7-20.

17. Farooq RK, Asghar K, Kanwal S, Zulqernain A. Role of inflammatory cytokines in depression: focus on interleukin-1ß. Biomed Reports. 2017;6(1):15-20. https://doi.org/10.3892/br.2016.807.

18. Dantzer R. Cytokine, sickness behavior, and depression. Immunol Allergy Clin N Am. 2009;29(2):247-64. https://doi.org/10.1016/j.iac.2009.02.002.

19. Raison $\mathrm{CL}$, Capuron L, Miller AH. Cytokines sing the blues: inflammation and the pathogenesis of depression. Trends Immunol. 2006;27(1):24-31. https:// doi.org/10.1016/j.it.2005.11.006.

20. Gialluisi A, Bonaccio M, Di Castelnuovo A, Costanzo S, De Curtis A, Sarchiapone M, Cerletti C, Donati MB, de Gaetano G, lacoviello L, Moli-Sani Study Investigators. Lifestyle and biological factors influence the relationship between mental health and low-grade inflammation. Brain Behav Immun. 2020;85:4-13. https://doi.org/10.1016/j.bbi.2019.04.041.

21. Patel A. Review: the role of inflammation in depression. Psychiatr Danub. 2013;25(Suppl 2):S216-23.

22. Lin BD, Alkema A, Peters T, Zinkstok J, Libuda L, Hebebrand J, et al. Assessing causal links between metabolic traits, inflammation and schizophrenia: a univariable and multivariable, bidirectional Mendelianrandomization study. Int J Epidemiol. 2019;48(5):1505-14. https://doi.org/1 0.1093/ije/dyz176.

23. Appay V, Sauce D. Immune activation and inflammation in HIV-1 infection: causes and consequences. J Pathol. 2008 Jan;214(2):231-41. https://doi. org/10.1002/path.2276.

24. Merrill JE, Martínez-Maza O. Cytokines in AIDS-Associated Nervous and Immune System Dysfunction. In 1993. p. 243-266.

25. Weiss L, Haeffner-Cavaillon N, Laude M, Gilquin J, Kazatchkine MD. HIV infection is associated with the spontaneous production off interleukin-1 (IL-1) in vivo and with an abnormal release off IL-1aaL in vitro. AIDS. 1989; 3(11):695-700. https://doi.org/10.1097/00002030-198911000-00002.

26. Kedzierska K, Crowe SM. Cytokines and HIV-1: interactions and clinical implications. Antivir Chem Chemother. 2001;12(3):133-50. https://doi.org/1 $0.1177 / 095632020101200301$.

27. Schiepers OJG, Wichers MC, Maes M. Cytokines and major depression. Prog Neuro-Psychopharmacol Biol Psychiatry. 2005;29(2):201-17. https://doi.org/1 0.1016/j.pnpbp.2004.11.003

28. Maes M, Bosmans E, De Jongh R, Kenis G, Vandoolaeghe E, Neels H. Increased serum IL-6 and IL-1 receptor antagonist concentrations in major depression and treatment resistant depression. Cytokine. 1997;9(11):853-8. https://doi.org/10.1006/cyto.1997.0238.

29. Norcini Pala A, Steca P, Bagrodia R, Helpman L, Colangeli V, Viale P, et al. Subtypes of depressive symptoms and inflammatory biomarkers: an exploratory study on a sample of HIV-positive patients. Brain Behav Immun. 2016;56:105-13. https://doi.org/10.1016/j.bbi.2016.02.013.

30. Paykel ES. Life events and affective disorders. Acta Psychiatr Scand. 2003; 108(s418):61-6. https://doi.org/10.1034/j.1600-0447.108.s418.13.x.

31. Slavich GM. Life stress and health. Teach Psychol. 2016;43(4):346-55. https:// doi.org/10.1177/0098628316662768.

32. Hardy P, Gorwood P. [Impact of life events in the course of depression]. Encephale. 1993;19 Spec No:481-9.

33. Brown GW. Life events and endogenous depression. Arch Gen Psychiatry. 1994;51(7):525-34. https://doi.org/10.1001/archpsyc.1994.03950070017006.

34. Kendler KS, Thornton LM, Prescott CA. Gender differences in the rates of exposure to stressful life events and sensitivity to their Depressogenic effects. Am J Psychiatry. 2001;158(4):587-93. https://doi.org/10.1176/appi.a jp.158.4.587.

35. Berrettini WH. Molecular linkage studies of bipolar disorders. Bipolar Disord. 2001;3(6):276-83. https://doi.org/10.1034/j.1399-5618.2001.30603.x.

36. Nkinda L, Patel K, Njuguna B, Ngangali JP, Memiah P, Bwire GM, et al. C Reactive protein and interleukin - 6 levels among human immunodeficiency virus -infected patients with dysglycemia in Tanzania. BMC Endocr Disord.
2019;19(1):77. [cited 2021 Apr 10] Available from: https://bmcendocrdisord. biomedcentral.com/articles/10.1186/s12902-019-0407-y.

37. Riley L, Guthold R, Cowan M, Savin S, Bhatti L, Armstrong T, et al. The world health organization STEPwise approach to noncommunicable disease riskfactor surveillance: methods, challenges, and opportunities. Am J Public Health. 2016;106(1):74-8. https://doi.org/10.2105/AJPH.2015.302962.

38. The Medical Outcomes Study HIV Health Survey (MOS-HIV). https://www. jhsph.edu/research/affiliated-programs/medical-outcomes-study-HIV/. Accessed 27 Jan 2021.

39. STEPwise Approach to NCD Risk Factor Surveillance (STEPS). https://www. who.int/teams/noncommunicable-diseases/surveillance/systems-tools/steps. Accessed 1 Dec 2020.

40. Clyne B, Olshaker JS. The C-reactive protein. J Emerg Med. 1999;17(6):1019-25. https://doi.org/10.1016/S0736-4679(99)00135-3.

41. Lau B, Sharrett AR, Kingsley LA, Post W, Palella FJ, Visscher B, Gange SJ. Creactive protein is a marker for human immunodeficiency virus disease progression. Arch Intern Med. 2006;166(1):64-70. https://doi.org/10.1001/a rchinte.166.1.64.

42. Boulware DR, Hullsiek KH, Puronen CE, Rupert A, Baker JV, French MA, et al. Higher levels of CRP, D-dimer, IL-6, and hyaluronic acid before initiation of antiretroviral therapy (ART) are associated with increased risk of AIDS or death. J Infect Dis. 2011;203(11):1637-46. https://doi.org/10.1093/infdis/ jir134.

43. Shivakoti R, Yang WT, Berendes S, Mwelase N, Kanyama C, Pillay S, et al. Persistently elevated $\mathrm{C}$-reactive protein level in the first year of antiretroviral therapy, despite virologic suppression, is associated with HIV disease progression in resource-constrained settings. J Infect Dis. 2016;213(7):1074-8. https://doi.org/10.1093/infdis/jiv573.

44. Poudel-Tandukar K, Bertone-Johnson ER, Palmer PH, Poudel KC. C-reactive protein and depression in persons with human immunodeficiency virus infection: the positive living with HIV (POLH) study. Brain Behav Immun. 2014;42:89-95. https://doi.org/10.1016/j.bbi.2014.06.004.

45. Kim JR, Kim HN, Song SW. Associations among inflammation, mental health, and quality of life in adults with metabolic syndrome. Diabetol Metab Syndr. 2018;10(1):66. https://doi.org/10.1186/s13098-018-0367-9.

46. Kokai M, Kashiwamura SI, Okamura H, Ohara K, Morita Y. Plasma interleukin-18 levels in patients with psychiatric disorders. J Immunother. 2002;25(Suppl 1):S68-71.

47. Xu Y, Yue W, Shugart YY, Yuan J, Wang G, Wang HZ, et al. Potential involvement of the interleukin-18 pathway in schizophrenia. J Psychiatr Res. 2016;74:10-6. https://doi.org/10.1016/j.jpsychires.2015.12.013.

48. Wedervang-Resell K, Friis S, Lonning V, Smelror RE, Johannessen C, Reponen EJ, et al. Increased interleukin 18 activity in adolescents with early-onset psychosis is associated with cortisol and depressive symptoms. Psychoneuroendocrinology. 2020;112:104513. https://doi.org/10.1016/j. psyneuen.2019.104513.

49. Bossù P, Piras F, Palladino I, lorio M, Salani F, Ciaramella $A$, et al. Hippocampal volume and depressive symptoms are linked to serum IL-18 in schizophrenia. Neurol Neuroimmunol Neurolnflammation. 2015;2(4):e111. https://doi.org/10.1212/NXI.0000000000000111.

50. Mansur RB, Cunha GR, Asevedo E, Zugman A, Rizzo LB, Grassi-Oliveira R, et al. Association of serum interleukin- 6 with mental health problems in children exposed to perinatal complications and social disadvantage. Psychoneuroendocrinology. 2016;71:94-101. https://doi.org/10.1016/j. psyneuen.2016.05.015.

51. Teixeira AL, De Souza RT, Zanetti MV, Brunoni AR, Busatto GF, Zarate CA, et al. Increased plasma levels of soluble TNF receptors 1 and 2 in bipolar depression and impact of lithium treatment. Hum Psychopharmacol. 2015; 30(1):52-6. https://doi.org/10.1002/hup.2450.

52. Diniz BS, Teixeira AL, Talib LL, Mendonça VA, Gattaz WF, Forlenza OV. Increased soluble TNF receptor 2 in antidepressant-free patients with latelife depression. J Psychiatr Res. 2010;44(14):917-20. https://doi.org/10.1016/j. jpsychires.2010.02.008.

53. Postal M, Lapa AT, Sinicato NA, et al. Depressive symptoms are associated with tumor necrosis factor alpha in systemic lupus erythematosus. J Neuroinflammation. 2016;13:5. https://doi.org/10.1186/s12974-015-0471-9.

54. Kudo N, Yamamori H, Ishima T, Nemoto K, Yasuda Y, Fujimoto M. Plasma levels of soluble tumor necrosis factor receptor 2 (STNFR2) are associated with hippocampal volume and cognitive performance in patients with schizophrenia. Int J Neuropsychopharmacol. 2018;21(7):631-9. https://doi. org/10.1093/ijnp/pyy013. 
55. Wium-Anderson MK, Orsted DD, Nielsen SF, Nordestgaard BG. Elevated Creactive protein levels, psychological distres, and depression in 73131 individuals. JAMA Psychiatry. 2013;70(2):176-84. https://doi.org/10.1001/2 013.jamapsychiatry.102.

56. Raison $\mathrm{CL}$, Miller $\mathrm{AH}$. Is depression an inflammatory disorder? Curr Psychiatry Rep. 2011;13(6):467-75. https://doi.org/10.1007/s11920-011-02320.

57. Capuron L, Miller AH. Pharmacology \& Therapeutics Immune system to brain signaling: Neuropsychopharmacological implications is. Pharmacol Ther. 2011;130(2):226-38. https://doi.org/10.1016/j.pharmthera.2011.01.014.

58. Hashimoto K. Emerging role of glutamate in the pathophysiology of major depressive disorder. Brain Res Rev. 2009;61 (2):105-23. https://doi.org/10.101 6/j.brainresrev.2009.05.005.

59. Giudicessi JR, Ackerman BM. 2013. 基因的改变NIH public access. Bone. 2008;23(1):1-7.

60. Duivis $H E$, de Jonge P, Penninx BW, Na BY, Cohen BE, Whooley MA. Depressive symptoms, health behaviors, and subsequent inflammation in patients with coronary heart disease: prospective findings from the heart and soul study. Am J Psychiatry. 2011;168(9):913-20.

61. Diane E. Handy, Rita Castro JL. 基因的改变 NIH public access. Bone. 2011; 23(1):1-7.

62. Kim JW, Szigethy EM, Melhem NM, Saghafi EM, Brent DA. Inflammatory markers and the pathogenesis of pediatric depression and suicide: a systematic review of the literature. J Clin Psychiatry. 2014;75(11):1242-53. https://doi.org/10.4088/JCP.13r08898.

63. Kyrou I, Tsigos C. Stress hormones: physiological stress and regulation of metabolism. Curr Opin Pharmacol. 2009;9(6):787-93. https://doi.org/10.1016/ j.coph.2009.08.007

64. Wilson M, Wilson M. Men and women. Men Elders. 2018;19(2):106-41.

65. Gialluisi A, de Gaetano G, lacoviello L. New challenges from Covid-19 pandemic: an unexpected opportunity to enlighten the link between viral infections and brain disorders? Neurol Sci. 2020;41:1349-50. https://doi.org/1 0.1007/s10072-020-04444-z.

66. Kinyanda E, Hoskins S, Nakku J, Nawaz S, Patel V. Prevalence and risk factors of major depressive disorder in HIV/AIDS as seen in semi-urban Entebbe district, Uganda. BMC Psychiatry. 2011;11:205.

67. Jonsson G, Davies N, Freeman C, Joska J, Pahad S, Thom R, et al. Guideline: management of mental health disorders in HIV-positive patients. South Afr J HIV Med. 2013;14(4):155-65.

68. Bhatia MS, Munjal S. Prevalence of depression in people living with HIV/ AIDS undergoing art and factors associated with it. J Clin Diagnostic Res. 2014:8(10):WC01-4.

69. Niu L, Luo D, Liu Y, Silenzio VMB, Xiao S. The mental health of people living with HIV in China, 1998-2014: a systematic review. PLoS One. 2016;11(4): e0153489. https://doi.org/10.1371/journal.pone.0153489.

70. Ali GC, Ryan G, De Silva MJ. Validated screening tools for common mental disorders in low and middle income countries: a systematic review. PLoS One. 2016;11(6):1-15.

\section{Publisher's Note}

Springer Nature remains neutral with regard to jurisdictional claims in published maps and institutional affiliations.

Ready to submit your research? Choose BMC and benefit from:
- fast, convenient online submission
- thorough peer review by experienced researchers in your field
- rapid publication on acceptance
- support for research data, including large and complex data types
- gold Open Access which fosters wider collaboration and increased citations
- maximum visibility for your research: over 100M website views per year
At BMC, research is always in progress.
Learn more biomedcentral.com/submissions

